\title{
Factors that influence advance directives completion amongst terminally ill patients at a tertiary hospital in Kenya
}

Stephen Omondi, John Weru, Asim Jamal Shaikh and Gerald Yonga

\begin{abstract}
Background: An advance directive (AD) is a written or verbal document that legally stipulates a person's health care preference while they are competent to make decisions for themselves and is used to guide decisions on lifesustaining treatment in the event that they become incapacitated. AD can take the form of a living will, a limitation of care document, a do-not-resuscitate order, or an appointment of a surrogate by durable power of attorney. The completion rate of $A D$ varies from region to region, and it is influenced by multiple factors. The objectives of this study were to determine the proportion of terminally ill patients with $A D$ and to identify the factors that influence the completion of $A D$ amongst terminally ill patients at a tertiary hospital in Kenya.

Methods: The study was a retrospective survey. All available records of terminally ill patients seen at Aga Khan University Hospital, Nairobi, between July 2010 and December 2015, and that met the inclusion criteria were included in the study.
\end{abstract}

Results: In total, 216 records of terminally ill patients were analyzed: 89 records were of patients that had AD and 127 records were of patients that did not have AD. The proportion of terminally ill patients that had completed AD was $41.2 \%$. The factors that were associated with the completion of AD on bivariate analysis were history of ICU admission, history of endotracheal intubation, functional status of the patient, the medical specialty taking care of the patient, patient's caregiver discussing the AD with the patient, and a palliative specialist review. On multivariate regression analysis, discussion of $A D$ with a caregiver and patient's functional impairment were the factors with statistically significant association with completion of AD.

Conclusions: The proportion of terminally ill patients that had AD in their medical records was significant. However, most terminally ill patients did not have AD. Our data, perhaps the first on the subject in East Africa, suggest that most of the factors associated with AD completion mirrored those seen in other regions of the world. Discussion between patient and their physician and patient's functional impairment were the factors independently associated with completion of AD. Therefore, physicians need to be aware of the importance of discussions of AD with their patients.

Keywords: Advance directives, Palliative care, Terminal illness, Factors, Kenya

\footnotetext{
*Correspondence: stomjb@gmail.com

Aga Khan University-Kenya, Nairobi, Kenya
} 


\section{Background}

Advance care planning for end of life is practiced in many parts of the world. It is a process that results in a written document, an advance directive (AD), which legally stipulates a person's health care preference while they are competent to make decisions for themselves, and which is then used to guide decisions on lifesustaining treatment in the event that they become incapacitated.

The uptake of AD has been limited even in the countries where its use has existed for several years. The prevalence of $\mathrm{AD}$ in Australia was about $14 \%$ in one study, [1] and in a population in Canada, the prevalence of AD was $43.6 \%$ [2]. About a third of USA population have an $\mathrm{AD}$ [3]. At the hospital level, there is a low uptake in most branches of medicine other than oncology.

What is considered a good way to die differs from society to society [4]. The prevailing culture and the economic situation of a country determine the practice of end of life care in that country. Africa differs significantly from Western countries in terms of culture and economics. The factors that influence an individual's uptake of $\mathrm{AD}$ are complex. They include patient, caregiver, legal, institutional, cultural, and religious factors, and while these factors may be similar between two societies, they do not have the same prevalence or contribute equally in each society.

In Western societies, where the factors that influence $\mathrm{AD}$ have been studied the most, the studies have been predominantly among elderly populations. Most of these studies have been prospective population-based surveys. Lovell et al., in a systematic review, summarize factors that determine AD use amongst palliative care patients. It revealed that older age, college education, diagnosis of cancer, being white, previous illnesses, an individual's knowledge and attitude, a health care provider's knowledge and attitude, availability of hospice care, specialist palliative care treatment, and laws on $\mathrm{AD}$ were positively correlated with signing an AD. While suffering from dementia, being African American, having dependent children, avoidance of acknowledging death and dying, concerns about AD resulting in withdrawal of care, and lack of facilitative laws were among the factors hindering uptake of $\mathrm{AD}$ [5]. Overall, advanced age and terminal illness were the most common reasons for completing AD.

Advance directives are hardly completed in Africa and little has been done on this subject. The relevance of AD in an environment with limited health care facilities, as is the case in most countries in Africa, may itself be questionable. In such a setting, most patients do not have a true choice on end of life care since life-sustaining treatment may not be available. One can, however, still make the opposite argument that available health resources in these countries should be directed where they would have the most impact, and that one way of doing that would be to promote uptake of AD. A study addressing the question of relevance of $\mathrm{AD}$ amongst five focus groups in South Africa found that AD was considered relevant by all five focus groups [6]. There have also been concerted efforts led by WHO to develop palliative care in Africa to take care of the increasing number of terminally ill cancer and HIV patients $[7,8]$.

In most African societies, discussion of death and dying is considered a taboo. Yet, it is frowned upon when an individual takes unilateral decisions on issues of dying. The decisions on end of life care are preferably deferred to family members or community elders [9]. In Kenya, for example, $68.2 \%$ of respondents in one study indicated they would like a relative to be involved in end of life decision making [10]. The study was a population-based survey of public preferences and priorities for end of life care in Kenya done in Nairobi and Western Kenya. It found that the majority, $61.4 \%$, preferred quality of life over quantity, i.e., extending life. One's own home was the most commonly (51.1\%) preferred place to die [10].

Kenya does not have a law on AD, and where practiced, it is usually under institutional policy. At our hospital, the policy on end of life care was enacted in 2012. It offers guidance on when end of life care discussions should be initiated. It also provides suggestions to health care providers on the categories of patients that should be considered for end of life care discussions. Our hospital has a 280 -bed capacity. It is a private tertiary level hospital that provides specialty training in internal medicine, pediatrics, obstetrics and gynecology, surgery, anesthesiology, radiology, anatomic pathology, and clinical pathology. The Internal Medicine department has several subspecialties - oncology, cardiology, infectious diseases, pulmonology, gastroenterology, nephrology, critical care, dermatology, neurology, hematology, endocrinology, rheumatology, psychiatry, and palliative care. The palliative care unit has one specialist doctor who heads a team of allied professionals.

The objectives of our study were to determine the proportion of terminally ill patients with AD and to identify the factors that influence AD completion at our hospital.

\section{Methods}

We conducted a retrospective survey using all available records of terminally ill patients seen at Aga Khan University Hospital, Nairobi, between July 2010 and December 2015 , and that met the inclusion criteria of the study.

The process that was followed in identifying the files to include in the study is outlined in Fig. 1.

Terminal illness was defined as a disease that could not be cured or adequately treated and that was 


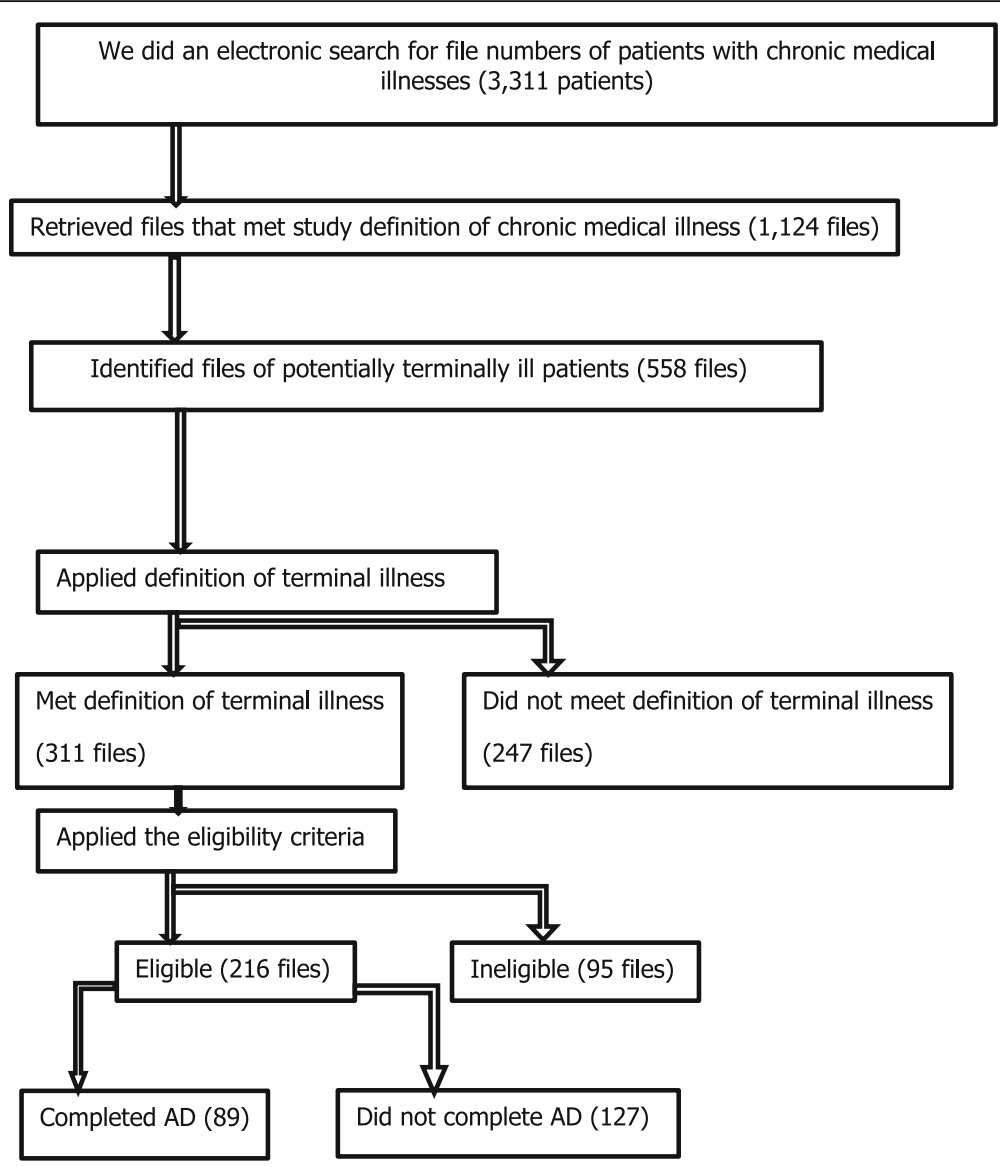

Fig. 1 Recruitment Process

reasonably expected to result in the death of the patient within a short period, which was arbitrarily defined as within six months. A file that had records of a living will, a limitation of care document, a do-not-resuscitate order, or an appointment of surrogate by durable power of attorney for health care was considered to denote that the patient had completed AD.

We included only records of patients that were or above age 18 years and whose first and last consultations at our hospital were at least three months apart.

We excluded a record without a diagnosis, a record that was indeterminate for the definition of terminal illness, a record that had no dates of first and last consultations, or one that had more than $30 \%$ of the questionnaire variables missing.

\section{Data management and analysis}

Stata version 14.1 was used to analyze the data. Chi square test was used to analyze the relationship between proportions of categorical variables in the subjects that completed $\mathrm{AD}$ and in those who did not complete $\mathrm{AD}$. Fisher's exact test was used to examine the same categorical variables to take care of the small sample size.
The factors found to be statistically significant in bivariate analysis were then subjected to multivariate regression analysis.

\section{Results}

The numbers of records that were found in the study are depicted in Fig. 1. The patients' characteristics are depicted in Table 1 . The diagnoses of study subjects are depicted in Table 2. The mean age of study subjects was 60.45 years; the median age was 63 years. The minimum and maximum ages were 19 years and 93 years, respectively. Figure 2 depicts a histogram of the patients ages.

In total, 216 records of terminally ill patients met the inclusion criteria: 89 were of patients that had advance directives and 127 were of those that did not have advance directives. These proportions are depicted in Fig. 3.

The most common type of advance directives was a limitation of care document at $58.3 \%$. Figure 4 depicts the types of $\mathrm{AD}$ that were completed by patients.

The proportion of terminally ill patients that had completed $\mathrm{AD}$ was $41.2 \%$. The factors that were associated with completion of $\mathrm{AD}$ on bivariate analysis were history of ICU admission, history of endotracheal intubation, 
Table 1 Patients' Characteristics

\begin{tabular}{|c|c|c|}
\hline \multicolumn{3}{|l|}{ Patients Characteristics } \\
\hline & $n$ & $\%$ \\
\hline \multicolumn{3}{|l|}{ Age Group } \\
\hline$<45$ years & 57 & 22.53 \\
\hline $45-65$ years & 88 & 34.78 \\
\hline$>65$ years & 108 & 42.69 \\
\hline \multicolumn{3}{|l|}{ Gender } \\
\hline Male & 113 & 52.31 \\
\hline Female & 103 & 47.69 \\
\hline \multicolumn{3}{|l|}{ Nationality } \\
\hline Kenyan & 183 & 84.72 \\
\hline Non-Kenyan & 83 & 15.28 \\
\hline \multicolumn{3}{|l|}{ Ethnicity } \\
\hline African & 151 & 69.91 \\
\hline Asian & 48 & 22.22 \\
\hline Caucasian & 13 & 6.02 \\
\hline Others & 4 & 1.85 \\
\hline \multicolumn{3}{|l|}{ Marital Status } \\
\hline Divorced & 3 & 1.4 \\
\hline Married & 164 & 76.64 \\
\hline Single & 18 & 8.41 \\
\hline Widowed & 29 & 13.55 \\
\hline \multicolumn{3}{|l|}{ Parental Status } \\
\hline A Parent & 189 & 87.5 \\
\hline Not a Parent & 27 & 12.5 \\
\hline \multicolumn{3}{|l|}{ Education } \\
\hline No formal Education & 5 & 2.43 \\
\hline Primary & 17 & 7.94 \\
\hline Secondary & 25 & 11.68 \\
\hline Tertiary & 167 & 78.04 \\
\hline \multicolumn{3}{|l|}{ Socio-economic class } \\
\hline Semi-skilled & 27 & 12.74 \\
\hline Unskilled & 86 & 40.57 \\
\hline Highly skilled & 99 & 46.7 \\
\hline \multicolumn{3}{|l|}{ Religion } \\
\hline Hindu & 20 & 9.35 \\
\hline Islam & 37 & 17.29 \\
\hline Judaism & 1 & 0.49 \\
\hline Protestant & 140 & 65.42 \\
\hline Catholic & 15 & 7.01 \\
\hline Others & 1 & 0.47 \\
\hline
\end{tabular}

the functional status of the patient, the medical specialty taking care of the patient, a caregiver discussing the $\mathrm{AD}$ with the patient, and a palliative care specialist reviewing the patient. The results of bivariate analysis of the factors associated with $\mathrm{AD}$ completion are depicted in Table 3.

On multivariate regression analysis, the discussion of $\mathrm{AD}$ with a caregiver and the patient's functional impairment were the only factors with statistically significant association with completion of AD. The results of the multivariate analysis are depicted in Table 4.

Sixty (67\%) the of subjects who had completed AD had their wishes honored by the attending doctors.

\section{Discussion}

This study was a retrospective survey to determine the proportion of terminally ill patients that had completed $\mathrm{AD}$ and to determine the factors that were associated with AD completion.

We found that $41.2 \%$ of terminally ill patients had completed AD. Sittisombut et al. found even a higher completion rate $(80 \%)$ amongst terminally ill patients in Thailand [11]. Both our study and Sittisombut's looked at terminally ill patients, and this could explain why our studies had proportionally higher completion rate of $\mathrm{AD}$ compared to, for example, Mezey et al.'s study, in which only $20.4 \%$ had completed AD but which included both terminally ill and non-terminally ill patients [12]. The rate of $\mathrm{AD}$ completion in our study was not very high when compared to the rates of $\mathrm{AD}$ completion reported in the West. It can certainly be improved with better participation of the primary physicians.

Limitation of care documents and DNR orders were the most common type of $\mathrm{AD}$ completed in our study. There were only three living will documents completed. There was no single power of attorney by proxy documentation filled. Our findings contrast with those of the Alano et al. study where up to $85 \%$ of subjects had completed a living will [13]. The lower proportion of living will documents found in our study could be attributed to the lack of $\mathrm{AD}$ laws in our country, but cultural factors may also have played a role.

There was no significant association between ethnicity and completion of $\mathrm{AD}$ in our study. In the USA, African-Americans and other minority ethnic groups were less likely to have AD compared to the Caucasians [14]. In our study the majority of patients were African (69.92\%) followed by Asians (22.22\%). Caucasians constituted only $6.02 \%$ of patients. Completion of $\mathrm{AD}$ is known to be generally higher amongst Caucasians, and they were under-represented in our study. In addition, a pertinent point to note is that our hospital is mostly patronized by well-educated, high and middle class clients, irrespective of their ethnicity. The homogenous socioeconomic status of our patients could thus be the reason an association between ethnicity and $\mathrm{AD}$ completion was not seen in our study. 
Table 2 Diagnoses of subjects with and without $A D$

\begin{tabular}{|c|c|c|}
\hline & Patient with $A D$ & Patient without AD \\
\hline \multicolumn{3}{|l|}{ Oncology } \\
\hline Brain Cancer & 1 & 2 \\
\hline Breast Cancer & 16 & 16 \\
\hline Esophageal Cancer & 2 & 3 \\
\hline Cervical Cancer & 5 & 6 \\
\hline Cholangiocarcinoma & 3 & 8 \\
\hline Colorectal Carcinoma & 8 & 6 \\
\hline Endometrial Cancer & 2 & 1 \\
\hline Gastric Cancer & 8 & 1 \\
\hline Hepatocellular Carcinoma & 9 & 10 \\
\hline Lung Cancer & 8 & 6 \\
\hline Nasopharyngeal Carcinoma & 2 & 4 \\
\hline Neuroendocrine Cancer & 2 & 1 \\
\hline Ovarian Cancer & 2 & 0 \\
\hline Pancreatic Cancer & 4 & 1 \\
\hline Prostate Cancer & 3 & 8 \\
\hline \multicolumn{3}{|l|}{ Non-Oncology } \\
\hline Advanced HIV & 0 & 6 \\
\hline End Stage Renal Disease & 3 & 19 \\
\hline Advanced Heart Failure & 2 & 16 \\
\hline Advanced Dementia & 2 & 2 \\
\hline Advanced Interstitial Lung Disease & 3 & 4 \\
\hline Advanced COPD & 2 & 2 \\
\hline Advanced Liver Cirrhosis & 2 & 5 \\
\hline
\end{tabular}

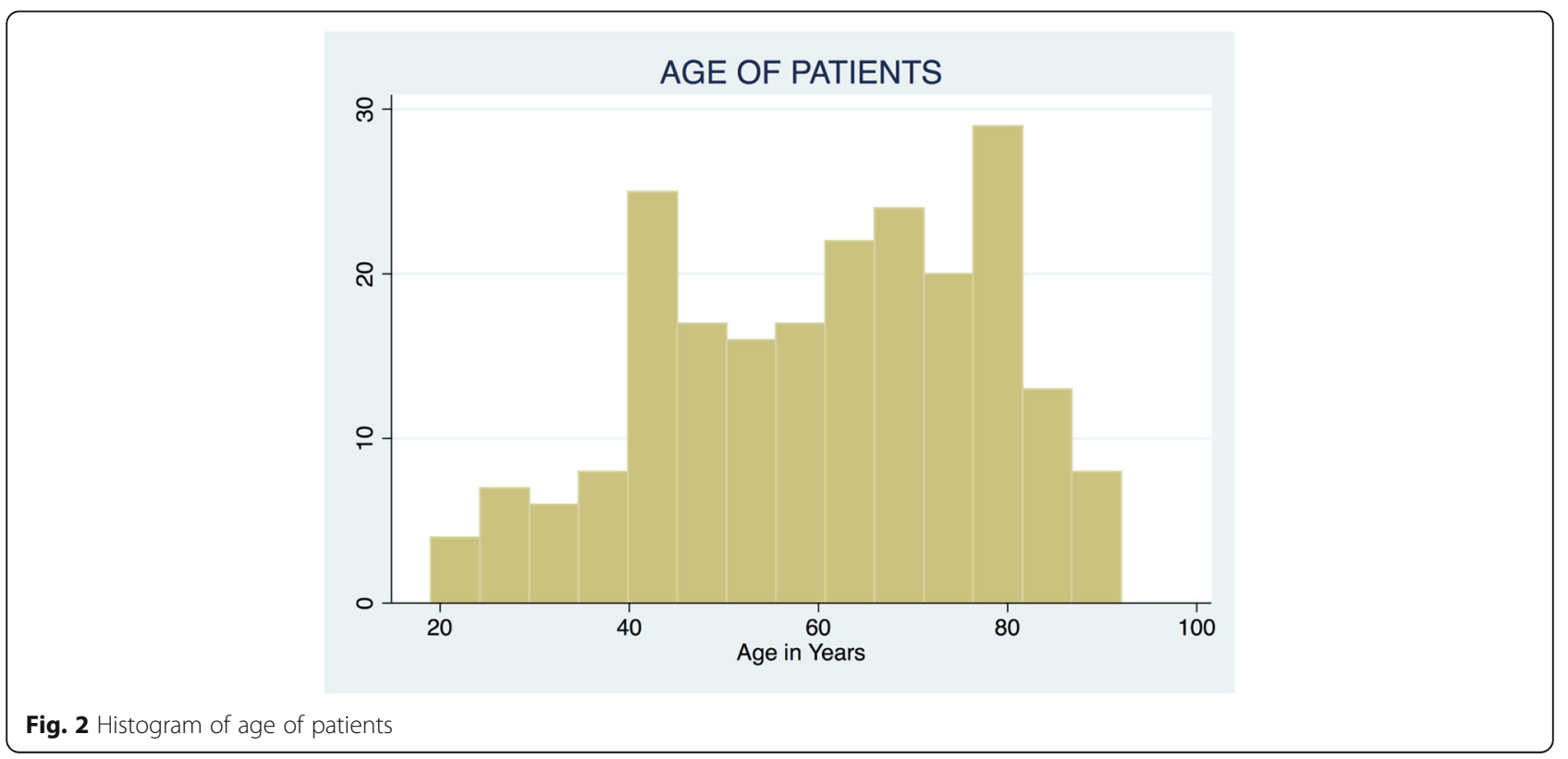




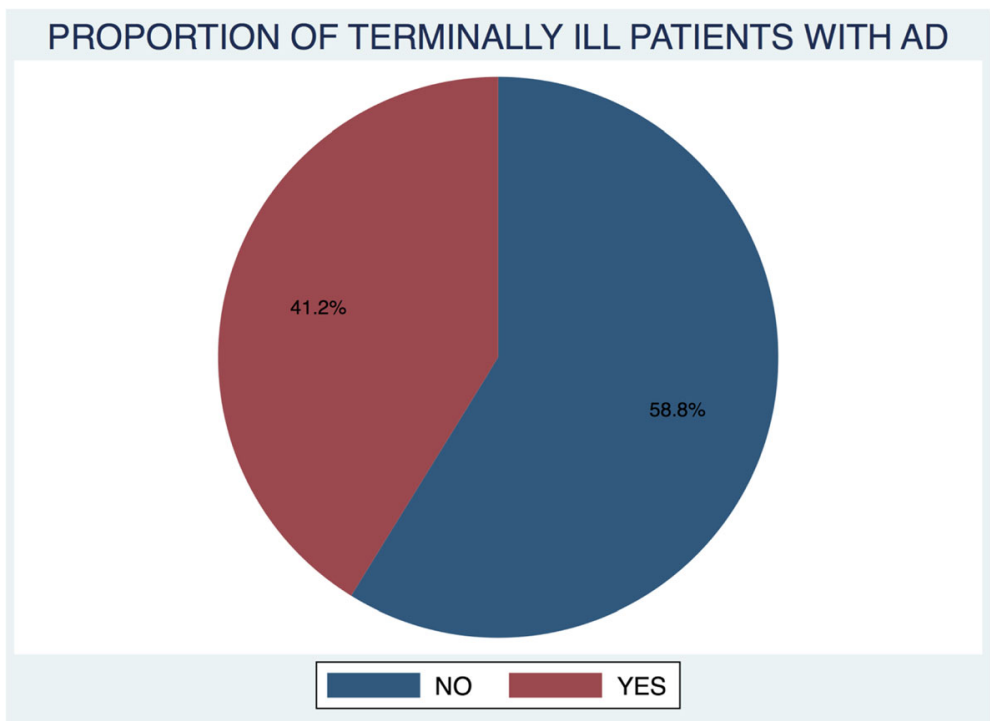

Fig. 3 proportion of terminally ill patients with $A D$

Many patients learn about advance directives for the first time from their doctor. Therefore, promoting physicians' understanding of $\mathrm{AD}$ is one way of promoting the uptake of AD [15]. Similar to the positive association between caregivers discussing $\mathrm{AD}$ with their patients and completion of $\mathrm{AD}$ that was found in this study, Walker et al. found that after controlling for demographic and clinical confounders, physicians had the most important role in determining uptake of $\mathrm{AD}$. Palliative care includes advance care planning as one of the services offered, and it is expected, as was seen in this study, that a palliative care specialist consultation would be associated with a higher completion rate of $\mathrm{AD}$. Therefore, health institutional policies and protocols that ensure attending physicians discuss AD with all terminally ill patients have great potential to improve completion rates.

Moody et al. found functional impairment to be correlated with completion of $\mathrm{AD}$ [16]. We similarly found that the degree of functional impairment as measured by the Karnofsky performance scale index was positively associated with completion of AD. In interview-based studies in the United states, when patients were asked what factors influenced them to complete $\mathrm{AD}$, functional impairment, loss of independence, previous experiences

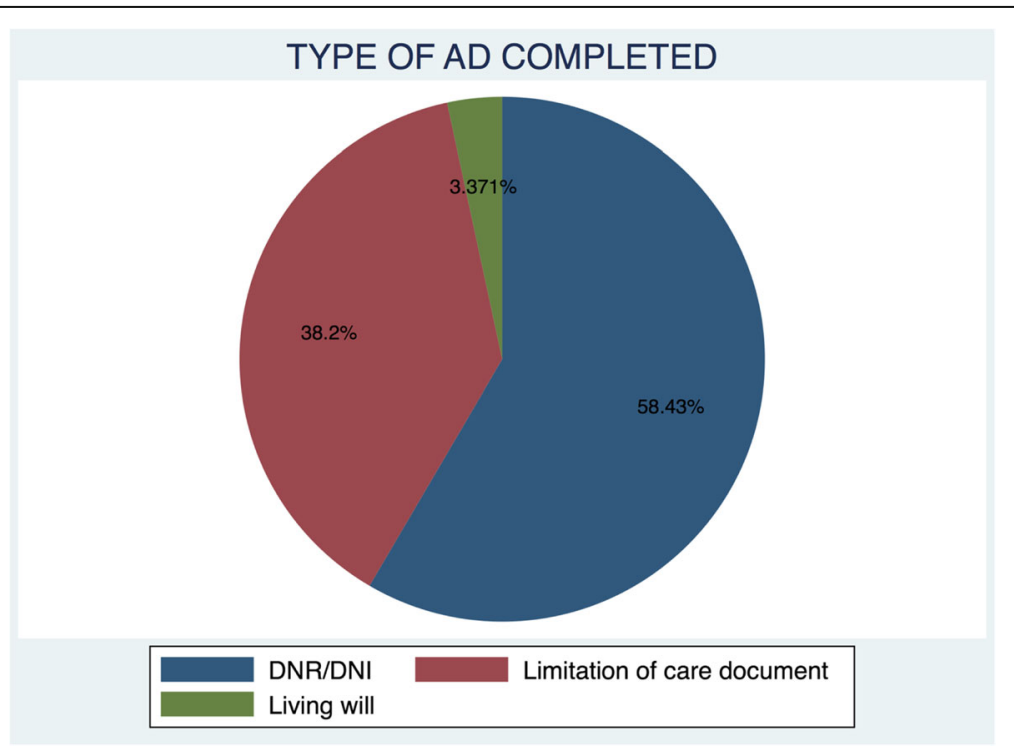

Fig. 4 Types of AD Completed 
Table 3 Comparison of subjects with and without AD

\begin{tabular}{|c|c|c|c|c|c|c|}
\hline & $n=216$ & Pati & $(n=89)$ & Patie & $(n=127)$ & \\
\hline & $\%$ & $\bar{n}$ & $\%$ & $n$ & $\%$ & $P$ Value \\
\hline Age Group & & & & & & 0.921 \\
\hline$<45$ years & 21.3 & 19 & 21.35 & 27 & 21.26 & \\
\hline 45-65 years & 35.19 & 30 & 33.71 & 46 & 36.22 & \\
\hline$>65$ years & 43.52 & 40 & 44.94 & 54 & 45.52 & \\
\hline Gender & & & & & & 0.903 \\
\hline Female & 47.69 & 42 & 47.19 & 61 & 48.73 & \\
\hline Male & 52.31 & 47 & 52.81 & 66 & 51.97 & \\
\hline Ethnicity & & & & & & 0.377 \\
\hline African & 69.91 & 67 & 75.28 & 84 & 66.14 & \\
\hline Asian & 22.22 & 18 & 20.22 & 30 & 23.62 & \\
\hline Caucasian & 6.02 & 3 & 3.37 & 10 & 7.87 & \\
\hline Others & 1.85 & 1 & 1.12 & 3 & 2.36 & \\
\hline Marital Status & & & & & & 0.313 \\
\hline Divorced & 1.4 & 1 & 1.12 & 2 & 1.6 & \\
\hline Married & 76.64 & 67 & 75.28 & 97 & 77.6 & \\
\hline Single & 8.41 & 11 & 12.36 & 7 & 5.6 & \\
\hline Widowed & 13.55 & 10 & 11.24 & 19 & 15.2 & \\
\hline Parental Status & & & & & & 0.715 \\
\hline A Parent & 87.5 & 77 & 86.52 & 112 & 88.19 & \\
\hline Not a Parent & 12.5 & 12 & 13.48 & 15 & 11.81 & \\
\hline Number of Children & & & & & & 0.779 \\
\hline No Child & 12.98 & 12 & 13.95 & 15 & 12.3 & \\
\hline 1-5 Children & 64.42 & 53 & 61.63 & 81 & 66.39 & \\
\hline$\geq 5$ Children & 22.6 & 21 & 24.43 & 26 & 21.31 & \\
\hline Education & & & & & & 0.221 \\
\hline No formal Education & 2.43 & 4 & 4.49 & 1 & 0.8 & \\
\hline Primary & 7.94 & 9 & 10.11 & 8 & 6.4 & \\
\hline secondary & 11.68 & 9 & 10.11 & 16 & 12.8 & \\
\hline Tertiary & 78.04 & 67 & 75.28 & 100 & 80 & \\
\hline Socio-economic class & & & & & & 0.889 \\
\hline Unskilled & 40.57 & 38 & 42.7 & 48 & 39.02 & \\
\hline Semi-skilled & 12.74 & 11 & 12.36 & 16 & 13.01 & \\
\hline highly skilled & 46.7 & 40 & 44.94 & 59 & 47.97 & \\
\hline Religion & & & & & & 0.189 \\
\hline Hindu & 9.35 & 4 & 4.55 & 16 & 12.7 & \\
\hline Islam & 17.29 & 18 & 20.45 & 19 & 15.08 & \\
\hline Judaism & 0.49 & 0 & 0 & 1 & 0.79 & \\
\hline Protestant & 65.42 & 59 & 67.05 & 81 & 64.29 & \\
\hline Catholic & 7.01 & 6 & 6.82 & 9 & 7.14 & \\
\hline Others & 0.47 & 1 & 1.14 & 0 & 0 & \\
\hline Insurance Status & & & & & & 0.295 \\
\hline Has Health Insurance & 61.35 & 57 & 65.52 & 70 & 58.33 & \\
\hline
\end{tabular}


Table 3 Comparison of subjects with and without AD (Continued)

\begin{tabular}{|c|c|c|c|c|c|c|}
\hline No Health Insurance & 38.65 & 30 & 34.48 & 50 & 41.67 & \\
\hline AD Discussion & & & & & & $<0.05$ \\
\hline Caregiver Discussed AD & 48.15 & 82 & 92.13 & 22 & 17.32 & \\
\hline Caregiver didn't Discuss AD & 51.85 & 7 & 7.87 & 105 & 82.68 & \\
\hline No. of Morbidities & & & & & & 0.25 \\
\hline 1 - 3 Morbidities & & 47 & 52.81 & 51 & 40.16 & \\
\hline$>3$ Morbidities & 38.43 & 28 & 31.46 & 55 & 43.31 & \\
\hline Number of Admission & & & & & & 0.43 \\
\hline 1 - 3 Admissions & 93.98 & 85 & 95.51 & 118 & 92.91 & \\
\hline$>3$ Admissions & 6.02 & 4 & 4.49 & 9 & 7.09 & \\
\hline Specialty & & & & & & $<0.05$ \\
\hline Oncology & 68.52 & 75 & 84.27 & 73 & 57.48 & \\
\hline Non-Oncology & 31.48 & 14 & 15.73 & 54 & 42.52 & \\
\hline History of Surgery & & & & & & 0.201 \\
\hline History of Major Surgery & 9.14 & 4 & 4.49 & 11 & 9.09 & \\
\hline No History of Major Surgery & 92.86 & 85 & 9551 & 110 & 90.91 & \\
\hline ICU Admission & & & & & & $<0.05$ \\
\hline Previous ICU Admission & 40.47 & 20 & 22.47 & 69 & 53.17 & \\
\hline No Previous ICU Admission & 59.53 & 67 & 77.53 & 59 & 46.83 & \\
\hline Intubation History & & & & & & $<0.05$ \\
\hline Previous Intubation & 34.42 & 17 & 19.1 & 57 & 45.24 & \\
\hline No Previous Intubation & 65.52 & 72 & 80.9 & 69 & 54.76 & \\
\hline Palliative Care Consult & & & & & & $<0.05$ \\
\hline Palliative Care Consult & 54.88 & 71 & 80.68 & 47 & 37.01 & \\
\hline No Palliative Care Consult & 45.12 & 17 & 19.88 & 80 & 62.99 & \\
\hline Functional Status & & & & & & $<0.05$ \\
\hline Functional Impairment & 83.33 & 82 & 92.13 & 98 & 77.17 & \\
\hline No Functional Impairment & 16.67 & 7 & 7.87 & 29 & 22.83 & \\
\hline Household Composition & & & & & & 0.186 \\
\hline Lives alone & 7.87 & 10 & 11.24 & 7 & 5.51 & \\
\hline Lives with Immediate Family & 64.35 & 52 & 58.43 & 87 & 68.5 & \\
\hline Lives with Extended Family & 27.78 & 27 & 30.34 & 33 & 25.58 & \\
\hline
\end{tabular}

with critical care, or experiencing a friend or relative undergo a prolonged admission in critical care were some of the factors mentioned $[12,17]$. In our study, we found a similar association between completion of $\mathrm{AD}$ and history of critical care admission or endotracheal intubation. We did not, however, find an association between completion of $\mathrm{AD}$ and the number of comorbidities, the number of hospital admissions, or the history of major surgery, all of which have been found to be positively correlated with $\mathrm{AD}$ completion in other studies.

Lovell et al., in a systematic review of factors that influence $\mathrm{AD}$ completion amongst palliative care patients, reported that history of malignancy was positively correlated with completion of AD. They also reported that diagnoses of chronic obstructive pulmonary disease (COPD) and dementia were negatively correlated with completion of AD [5]. Butler el al found that most heart failure patients did not have AD documented in their files [18]. In our study, there was no independent association found between a diagnosis of malignancy and $\mathrm{AD}$ completion, but as was found in the Butler et al. study, there was a negative association between a heart disease diagnosis and completion of AD.

In our study, only six (2.78\%) patients had HIV, and none of them had completed AD. All of them had wellcontrolled disease. Barocas et al. studied AD completion 
Table 4 Multivariate analysis of factors associated with AD completion

\begin{tabular}{|c|c|c|c|c|}
\hline \multirow[b]{2}{*}{ Caregiver discussed AD } & \multirow{2}{*}{$\begin{array}{l}\text { RRR }^{\mathrm{a}} \\
40.56891\end{array}$} & \multirow{2}{*}{$\begin{array}{l}P \text { Value } \\
<0.05\end{array}$} & \multicolumn{2}{|c|}{$\begin{array}{l}\text { [95\% Confidence } \\
\text { Interval] }\end{array}$} \\
\hline & & & 15.05035 & 109.3554 \\
\hline Previous ICU ${ }^{\mathrm{b}}$ Admission & 0.6650326 & 0.582 & 0.1558932 & 2.836996 \\
\hline Intubation history & 0.4509578 & 0.304 & 0.0987241 & 2.059912 \\
\hline Palliative care consult & 1.43966 & 0.474 & 0.5305328 & 3.906678 \\
\hline Functional Impairment & 4.169589 & 0.021 & 1.243331 & 13.98298 \\
\hline Specialty & 1.010565 & 0.986 & 0.3145422 & 3.246757 \\
\hline
\end{tabular}

amongst people living with HIV and found that only a quarter of people living with HIV had completed AD. The factors associated with AD completion in their study were diagnosis of AIDS, neurological, cardiovascular, chronic kidney disease, or malignancy. They made the point that since HIV had become a chronic disease and patients were more likely to die from other comorbid conditions, opportunities were being missed to complete $\mathrm{AD}$ in this population.

The mean age in our study was 60.45 years. There was no association of age with completion of $\mathrm{AD}$ in our study. The mean age in Sittisombut et al. study was 57.5 years. The mean age in Mezey et al. study was 52 years. In the Sittisombut et al. study, most subjects were above age 60 years. They did not, however, report the association of age with $\mathrm{AD}$ completion. In the studies done in the Western countries, advanced age is an important determinant of $\mathrm{AD}$ completion [2, 19]. These studies were however not among terminally ill patients. It is possible that a diagnosis of terminal illness eliminates the influence of advanced age in $\mathrm{AD}$ completion.

We did not find an association between parental status and $\mathrm{AD}$ completion. Neither was there an association between the number of children a subject had and completion of AD. Nilsson et al. found a positive correlation between having dependent children and completion of AD [20]. Most of our subjects were married, but there was no association between marital status and AD completion. It is not clear why family dynamics as reflected by the factors mentioned here had no association with $\mathrm{AD}$ completion. It could be because of the small sample size. For example, very few subjects in our study lived alone.

One's occupation type or whether they had medical insurance did not have an association with completion of $\mathrm{AD}$ in our study. One of the barriers to completion of AD found among the African-Americans was lower socioeconomic status [21]. In a hospital based study, Mezey et al. found a positive correlation between one's salary and one's health insurance status with completion of $\mathrm{AD}$ [12]. The association between $\mathrm{AD}$ completion and cost may not have been found in our study because it was done in a tertiary private hospital where most patients had health insurance.

Most of the subjects in our study were non-Catholic Christians (65.42\%) or Muslims (17.29\%). There was, however, no significant association found between religion and completion of $\mathrm{AD}$.

The proportions of males and females in our study were $52.31 \%$ and $47.69 \%$, respectively. Perkin's et al. addressed the role of gender in completion of AD. They found that men preferred death over futile care, and that men addressed only the functional aspects of end of life care. This contrasted with women who addressed other aspects as well [22]. In our study, there was no significant difference between proportions of males and females who completed AD.

The majority of patients in our study had obtained tertiary level education (78.04\%). The proportion of patients with tertiary education was higher in the people who did not complete advance directives (80\%) compared to those who had completed (75.28\%). However, education level attained did not have a statistically significant association with completion of $\mathrm{AD}$ in our study. Mezey et al. found education to be the most important factor in determining uptake of $\mathrm{AD}$ [12]. In another hospital-based study in Thailand, Sittisombut et al. the majority of patients had attained grade 4-6 level of education, with only about one third having attained above grade 9 level education. In their study, as was in ours, there was no correlation between education and completion of $\mathrm{AD}$ [11]. One reason why our results are similar to Sittisombut's could be the fact that in both studies the decisions to complete $\mathrm{AD}$ were made in most cases by the patient after discussions with their family, as opposed to an individualistic approach to AD completion.

There are patient factors associated with $\mathrm{AD}$ such as knowledge and attitude of patients that we could not study due to the retrospective nature of our study. There are also aspects of patient-physician relationship important for AD completion that we could not study. The role played by lack of laws on AD in Kenya could also not be studied. The influence of patients' relatives in influencing AD could also not be studied.

Due to the retrospective nature of our study, we could not focus on the role of religion and spirituality, patients' preexisting knowledge about advanced directives, patient-physician relationship, and influence of the relatives on decision making. However, all these factors are known to play a role in AD completion [23] [24].

Despite these limitations, our study shows that the factors associated with AD in Kenya are not different from those reported in the studies done in Western countries. 
It also re-demonstates the important role played by physicians in promoting AD use. Despite reporting from a developing country, our study demonstrates good uptake of $\mathrm{AD}$ in our hospital amongst terminally ill patients.

\section{Conclusion}

The proportion of terminally ill patients that had AD in their medical records was significant, however, most terminally ill patients did not have AD. Most of the factors associated with $\mathrm{AD}$ completion were the same as those seen in other regions of the world. Among them, discussion between a patient and their physician and functional impairment of the patient were the factors independently associated with completion of $\mathrm{AD}$. We conclude that physician involvement and early discussion with the patients are key components associated with $\mathrm{AD}$ completion. Similar but larger studies, done prospectively and incorporating patients from public hospitals, could identify other factors that could be improved to enhance completions of $\mathrm{AD}$ in our population. However, some factors known to influence AD completion in the United States of America and Western European countries such as age did not have a correlation with $\mathrm{AD}$ in our study, perhaps reflecting a relatively younger population in our setup.

To improve uptake of $\mathrm{AD}$ in our setting, we should encourage more physician - patient discussion as this was the main modifiable influence of $\mathrm{AD}$ uptake in our setting.

\section{Acknowledgments}

We wish to acknowledge Dr. Mary Kaniu who assisted with data collection and Ms Sandra Obaje who proofread the final manuscript. Aga Khan University Hospital, Nairobi, provided $\$ 50$ for purchase of stationery that was used in this study.

\section{Funding}

Aga Khan University Hospital, Nairobi, provided \$50 for purchase of stationery that was used in this study. They did not take part in or influence the study design, data collection and analysis, and drafting of the manuscript.

\section{Availability of data and materials}

The datasets used and/or analyzed during the current study available from the corresponding author and from the Dean's office, Aga Khan University Hospital, Nairobi, on reasonable request.

\section{Authors' contributions}

This paper was part of my dissertation work for a Master's degree in Internal Medicine. My co-authors were my supervisors. GY was my methodology supervisor, while AJ and JW were my content supervisors. All authors read and approved the final manuscript.

\section{Competing interests}

The authors declare that they have no competing interests.

\section{Consent for publication}

Not applicable.

\section{Ethics approval and consent to participate}

We obtained exemption from hospital ethical approval committee because this study was not to identify any subject by name and was not to contact any subjects in person. The need to obtain consent from patients or their relatives for patients' data to be used in this study was also waived by the Aga Khan University Hospital, Nairobi, ethical committee because this study was not to identify any subject by name and was not to contact any subjects.

Received: 5 October 2016 Accepted: 19 January 2017

Published online: 25 January 2017

\section{References}

1. White B, Tilse C, Wilson J, Rosenman L, Strub T, Feeney R, Silvester W. Prevalence and predictors of advance directives in Australia. Intern Med J. 2014;44(10):975-80.

2. Wilson DM, Houttekier D, Kunju SA, Birch S, Cohen J, MacLeod R, Hewitt JA. A population-based study on advance directive completion and completion intention among citizens of the western Canadian province of Alberta. J Palliat Care. 2013;29(1):5-12.

3. Jackson JM, Rolnick SJ, Asche SE, Heinrich RL. Knowledge, attitudes, and preferences regarding advance directives among patients of a managed care organization. Am J Manag Care. 2009;15(3):177-86.

4. Walter T. Historical and cultural variants on the good death. BMJ [Br Med J]. 2003;327(7408):218-20

5. Lovell A, Yates P. Advance care planning in palliative care: a systematic literature review of the contextual factors influencing its uptake 2008-2012. Palliat Med. 2014;28(8):1026-35.

6. Stanford J, Sandberg DM, Gwyther L, Harding R. Conversations worth having: the perceived relevance of advance care planning among teachers, hospice staff, and pastors in knysna, south africa. J Palliat Med. 2013;16(7):762-7.

7. Harding R, Higginson IJ. Palliative care in sub-Saharan africa. Lancet. 2005; 365(9475):1971-7.

8. Harding R, Selman L, Powell RA, Namisango E, Downing J, Merriman A, All Z, Gikaara N, Gwyther L, Higginson I. Research into palliative care in subSaharan africa. Lancet Oncol. 2013;14(4):e183-188.

9. Voltz R, Akabayashi A, Reese C, Ohi G, Sass HM. End-of-life decisions and advance directives in palliative care: a cross-cultural survey of patients and health-care professionals. J Pain Symptom Manag. 1998;16(3):153-62.

10. Downing J, Gomes B, Gikaara N, Munene G, Daveson BA, Powell RA Mwangi-Powell FN, Higginson IJ, Harding R. Public preferences and priorities for end-of-life care in Kenya: a population-based street survey. BMC Palliat Care. 2014;13(1):4.

11. Sittisombut S, Maxwell C, Love EJ, Sitthi-Amorn C. Effectiveness of advance directives for the care of terminally ill patients in Chiang Mai university hospital, Thailand. Nurs Health Sci. 2008;10(1):37-42.

12. Mezey MD, Leitman R, Mitty EL, Bottrell MM, Ramsey GC. Why hospital patients do and do not execute an advance directive. Nurs Outlook. 2000; 48(4):165-71.

13. Alano GJ, Pekmezaris R, Tai JY, Hussain MJ, Jeune J, Louis B, El-Kass G, Ashraf MS, Reddy R, Lesser M, et al. Factors influencing older adults to complete advance directives. Palliat Support Care. 2010;8(03):267-75.

14. Rhodes RL, Batchelor K, Lee SC, Halm EA. Barriers to end-of-life care for African americans from the providers' perspective: opportunity for intervention development. Am J Hosp Palliat Care. 2015;32(2):137-43.

15. Johnston SC, Pfeifer MP, McNutt R. The discussion about advance directives. Patient and physician opinions regarding when and how it should be conducted. End of life study group. Arch Intern Med. 1995;155(10):1025-30.

16. Moody LE, Small BJ, Jones CB. Advance directives preferences of functionally and cognitively impaired nursing home residents in the united states. J Appl Gerontol. 2002;21(1):103-18.

17. Cugliari A, Miller T, Sobal J. FActors promoting completion of advance directives in the hospital. Arch Intern Med. 1995;155(17):1893-8.

18. Butler J, Binney Z, Kalogeropoulos A, Owen M, Clevenger C, Gunter D, Georgiopoulou V, Quest T. Advance directives among hospitalized patients with heart failure. JACC Heart Fail. 2015;3(2):112-21.

19. Gordon NP, Shade SB. Advance directives are more likely among seniors asked about end-of-life care preferences. Arch Intern Med. 1999;159(7):701-4.

20. Nilsson ME, Maciejewski PK, Zhang B, Wright AA, Trice ED, Muriel AC, Friedlander RJ, Fasciano KM, Block SD, Prigerson HG. Mental health, treatment preferences, advance care planning, location, and quality of death in advanced cancer patients with dependent children. Cancer. 2009; 115(2):399-409. 
21. West SK, Hollis M. Barriers to completion of advance care directives among African americans ages 25-84: a cross-generational study. Omega. 2012; 65(2):125-37.

22. Perkins HS, Cortez JD, Hazuda HP. Advance care planning: does patient gender make a difference? Am J Med Sci. 2004;327(1):25-32.

23. Steinberg SM. Cultural and religious aspects of palliative care. Int J Crit IIIn Inj Sci. 2011;1(2):154-6.

24. Karches KE, Chung GS, Arora V, Meltzer DO, Curlin FA. Religiosity, spirituality, and end-of-life planning: a single-site survey of medical inpatients. J Pain Symptom Manag. 2012;44(6):843-51.

Submit your next manuscript to BioMed Central and we will help you at every step:

- We accept pre-submission inquiries

- Our selector tool helps you to find the most relevant journal

- We provide round the clock customer support

- Convenient online submission

- Thorough peer review

- Inclusion in PubMed and all major indexing services

- Maximum visibility for your research

Submit your manuscript at www.biomedcentral.com/submit 